\title{
Comparative Immunomodulatory Efficacy of Rosemary and Fenugreek Against Escherichia Coli- Infection via Suppression of Inflammation and Oxidative Stress in Broilers
}

\section{Sameh Mohamed Farouk ( $\nabla$ dr_smf_hist@vet.suez.edu.eg )}

Suez Canal University Faculty of Veterinary Medicine https://orcid.org/0000-0003-3097-1492

\section{Haidy G. Abd-El-Rahman}

Suez Canal University Faculty of Veterinary Medicine

\section{Osama A. Abdallah}

Suez Canal University Faculty of Veterinary Medicine

Nashwa G. El-Behidy

Veterinary Medicine Directorate of Damietta, Damietta

\section{Research Article}

Keywords: Fenugreek, Rosemary, Immunomodulatory, Antioxidant, E.coli, Histopathology, broiler.

Posted Date: February 26th, 2021

DOI: https://doi.org/10.21203/rs.3.rs-243370/v1

License: (c) (1) This work is licensed under a Creative Commons Attribution 4.0 International License.

Read Full License 


\section{Abstract}

Broilers are frequently infected with Escherichia coli (E.Coli) bacteria, which often leads to the emergence of many diseases and high economic losses. Hence, the present study was performed to assess the comparative efficacy of dietary rosemary and fenugreek, under E.Coli-infection in broilers, via evaluation of growth performance, biochemical indices, immunological response and histo-morphological changes. Eighty Cobb broilers were allotted to four equal groups ( $n=20$ chicks/group); control non-infected (CN), control infected $(\mathrm{Cl})$, rosemary infected $(\mathrm{RI})$ and fenugreek infected $(\mathrm{FI})$ groups. $\mathrm{RI}$ and $\mathrm{FI}$ groups showed a significant elevation in their body weight and body weight gain compared with $\mathrm{Cl}$ group. Moreover, both groups revealed a significant decline in serum aspartate and alanine aminotransferase activities, as well as uric acid and creatinine levels. Significant decreases of total antioxidant capacity, catalase and superoxide dismutase activities were noted among $\mathrm{Cl}$ chicks. Moreover, distinctly higher levels were evident in both RI and FI groups. Immunomodulatory markers assessment showed a significant increase in immunoglobulin $\mathrm{G}$ with a significant decline in interleukin- 6 level in both RI and FI groups, with the lowest IL-6 value within FI group. Histopathological evaluations focused on the deleterious effect associated with E-Coli infection of broilers' liver, kidney, intestine, spleen, bursa of fabricius, and thymus. A partial histological improvement was noticed among RI group, and nearly normal tissues were recorded in FI group. Overall, these findings suggest the ability of fenugreek to mitigate the adverse effects of E.Coliinfection on broiler performance and tissue pictures, through improvement of the chicken general health condition.

\section{Introduction}

In the global poultry industry, Escherichia coli (E-Coli) bacteria may lead to great economic losses each year due to high morbidity and mortality rates (Lau et al., 2010). E. coli infection is usually prevented or controlled with antibiotics. However, the emergence of the antibiotics and their continued use in poultry diets has raised many problems of varying severity including environmental pollution as well as the cross-resistance that may pose substantial risks for human health (Asai et al., 2011; Ghozlan et al., 2017). Notably, antibiotic growth inducers, in broiler feedings, have been banned by the European Commission. Therefore, many researchers have conducted their research studies to explore the potential use of effective alternatives to maintain livestock health. One possibility is the application of probiotics, prebiotics and herbaceous plants or their essential oils (Sarica et al., 2007), to replace antibiotics without negative impact on health or any loss of productivity (Demir et al., 2003; Maiorano et al., 2016). Herbal medicine has gained a wide interest in the feed industry, through their appetite and digestion-stimulating, antimicrobial, anti-inflammatory, anti-oxidative and immunostimulant properties (Mirzaei-Aghsaghali, 2012).

Rosemary (Rosmarinus officinalis), a widespread household plant, is used as a natural animal feed additive with its antibacterial, antifungal and antioxidant activities (Genena et al., 2008; Mohamed et al., 2016a), as well as it can be used as a flavoring agent for food, beverages, and cosmetics preparations (Ibarra et al., 2010). It has been documented to possess a number of therapeutic applications in medicine 
for curing or managing of different disease conditions such as inflammatory diseases, respiratory and GIT disorders (Al-Kassie and Abd-Al-Jaleel, 2011; El-Boshy et al., 2015). It is composed of 0.5\% volatile oil, flavonoids (diosmetin, genkwanin, diosmin, glucoside and luteolin), phenolic acids (rosmarinic, chlorogenic, neochlorogenic, labiatic and caffeic acids), carnosic acid, rosmaricine and isorosmaricine, triterpenic acids and others (Khan and Abourashed, 2010).

Historically, fenugreek (Trigonella foenum-fraecum), one of the oldest medicinal herbs, used in many domains including medicine, nutrition, fragrances, beverages, cosmetics and other industrial purposes (Djeridane et al., 2006). Its seeds are commonly used by people in Asia, Africa and Mediterranean countries as one of the ingredients in daily diets (Basch et al., 2003). In modern food technology, it is used as a food stabilizer, adhesive and emulsifying agent (Meghwal and Goswami, 2012). It is known to have several pharmacological properties (Benayad et al., 2014), including hypoglycemic (Sharma et al., 1990; Zia et al., 2001), hypocholesterolemic (Stark and Madar, 1993; Srinivasan, 2006), gastro-protective (Sujapandian et al., 2002), chemo-preventive (Amin et al., 2005), antioxidant (Kavirasan et al., 2007), antiinflammatory (Ahmadian et al., 2001) and appetite stimulation (Petit et al., 1993). Its pharmacological actions attributed to its constituents. Previously reported data on fenugreek phytochemical composition, highlighted the presence of alkaloids (Petropoulos, 2002), flavonoids and phenolic acids (Kenny et al., 2013), polysaccharides (Petropoulos, 2002), triterpenoids (Shang et al., 1998), steroidal sapogenins (Taylor et al., 1997) and nicotinic acid (Rajalakshmi et al., 1964). The fenugreek seeds contain about 7.5 $\%$ of total lipids; neutral lipids, glycolipids, and phospholipids. Additionally, it shows a high content of palmitic, linolenic acids, and former acid (Petropoulos, 2002), a large carbohydrate fraction (mucilaginous fiber and galactomannan); $20-30 \%$ proteins high in tryptophan and lysine; pyridine-type alkaloids; flavonoids; free amino acids (4-hydroxyisoleucine, arginine, lysine, and histidine); saponins; glycosides; vitamins, minerals, (28\%) mucilage, $5 \%$ of a stronger-smelling, bitter fixed volatile oils (Snehlata and Dande, 2012).

Therefore, the current study aimed to investigate the comparative ameliorative effects of broiler ration supplementation with two medicinal plants; rosemary leaves (Rosmarinus officinalis) and fenugreek seeds (Trigonella foenum-graecum), challenging with experimental infection of E. coli for six weeks, on growth performance, some selective biochemical, immunological and antioxidant parameters, along with histopathological changes associated with hepatic, renal, intestinal, splenic, thymic and bursal tissues.

\section{Materials And Methods}

\section{Experimental chicks, E-coli strain and natural products}

Eighty, one-day-old, apparently healthy commercial Cobb broiler were obtained from Alasma Masr Poultry Company, Egypt. E-coli strain 078 was obtained from Animal Health Research Institute, Ismailia, Egypt. Each chick inoculated with $0.5 \mathrm{ml}$ of E. coli 078 bacterial inoculum, colony-forming unit (CFU), at 7 days old as $0.25 \mathrm{ml}$ intranasal and $0.25 \mathrm{ml}$ by eye drop route. Rosemary leaves and fenugreek seeds were purchased from local commercial market of herbs and medicinal plants (Al-kateb Company, Egypt), were 
grounded by the home blender, and then were added to the balanced ration by $5 \mathrm{gm}$ plant powder $/ \mathrm{kg}$ diet for each.

\section{Chemicals and reagents}

All commercial test kits for Aspartate Aminotransferase (AST), Alanine Aminotransferase (ALT), Uric Acid (UA), Creatinine (Cr), Cholesterol (Ch) and Glucose (G) were obtained from BIO-Merieux (Brains/France) and Ticho-Diagnostic (Sees, France). Diagnostic kits for chicken interleukin-6 (IL-6) ELISA kit (Genorise Scientific, INC), Chicken immunoglobulin G (IgG) ELISA kit (Bethyl Laboratories, INC.), Superoxide Dismutase (SOD) ELISA kit (Kamiya Biomedical), Catalase (CAT) catalase assay kit (Cayman Chemical) and Total Antioxidant Capacity (TAC) OxiSelect ${ }^{\text {TM }}$ assay kit (Cell Biolabs, Inc) were used in the current study.

\section{Birds grouping and treatment schedule}

Upon arrival, birds were weighed and kept under standard hygienic conditions in floor pens covered with unused wood shavings litter, with free access to the balanced commercial basal ration and fresh tap water ad-libitum until the end of the experiment. The temperature was adjusted according to the age, $32^{\circ} \mathrm{C}$ at the first week and decreased $2^{\circ} \mathrm{C}$ per week. All chickens were vaccinated according to the vaccination schedule. Birds were then allotted into four equal groups ( $n=20$ chicks/group) as follow; control non-infected (CN) group, fed on balanced commercial ration free from any feed additives. Control infected (Cl) group, fed on balanced commercial ration free from any feed additive but experimentally infected with E-Coli at one week of age (Majo et al., 1997). Rosemary infected (RI) group, fed on balanced commercial ration supplied with rosemary at the level of $0.5 \%$ (5 gm rosemary leaves powder $/ \mathrm{kg}$ ration) from one day to 6 weeks old (Ghazalah and Ali, 2008) and experimentally infected with E-Coli at one week of age. Fenugreek infected ( $\mathrm{Fl})$ group, fed on balanced commercial ration supplied with fenugreek at the level of $0.5 \%$ ( $5 \mathrm{gm}$ fenugreek seed powder $/ \mathrm{kg}$ ration) from one day to 6 weeks old (Elbushra, 2012) and experimentally infected with E-Coli at one week of age.

\section{Growth performance parameters}

Each chick was individually weighed at beginning and end of the experiment (one day, 6th week old), respectively. Body weight gain (BWG) was calculated at 6 th weeks of the experiment by subtracting the body weight between two successive weights. Feed consumption (FC) was calculated / 6 weeks by subtracting the amount of feed remaining at the end of the 6th week from the amount of feed given at the beginning of the experiment. The amount of feed consumed was then divided by the weight gain of each group to obtain the Feed conversion ratio (FCR) (Nobo et al., 2012).

\section{Blood and tissue sampling}

At the end of the experiment, five chicks were randomly obtained from each group for blood and tissues collection. About $3 \mathrm{ml}$ of blood samples were obtained by the heart puncture of each bird and collected in a plain centrifuge tube and used for the preparation of serum for assay of biochemical, immunological and antioxidant parameters (TAC and CAT). After blood sampling, chicks were gently sacrificed and small 
specimens from the liver, kidney, intestine, spleen, thymus and bursa were obtained for histopathological examination. Furthermore, parts of liver and kidney were stored at $-20^{\circ} \mathrm{C}$ for the antioxidant assay (SOD).

\section{Sera biochemical parameters}

Blood sera were used for assessment of hepatic and renal injury biomarkers. ALT and AST activities was determined colorimetrically according to the method of Crowley (1967). UA was determined by uricase POD enzymatic colorimetric method according to Fossati et al. (1980). Cr occurred by photometric colorimetric test for kinetic measurement, methods without deproteinization, using readymade kits as described by the method of Owen et al., (1954). Serum glucose was determined according to Kinoshita et al. (1979). Cholesterol was determined by the enzymatic colorimetric method; CHOD-POD according to the method described by Allain et al. (1974).

\section{Cytokines estimation}

IL- 6 was assessed and IgG concentrations were calculated according to the method of Koivunen and Krogsrud (2006).

\section{Evaluation of antioxidant indices}

SOD concentration was measured according to Koivunen and Krogsrud (2006). CAT was assessed according to Wheeler et al., (1990), meanwhile TAC was calculated according to Hariane and Moya (2015).

\section{Histopathological examination}

Specimens of liver, kidney, intestine spleen, bursa, and thymus of sacrificed birds from all groups were freshly collected and then fixed in $10 \%$ neutral buffered formalin, embedded in paraffin, sectioned at 5$7 \mu \mathrm{m}$ thickness and finally stained with Hematoxylin and Eosin for histopathological examination. Routine histological processing was carried out according to the method of Suvarna et al., (2012).

\section{Statistical analysis}

Data collected from biochemical, immunological and antioxidant assays of treated groups were statically analyzed in compare to control group for the mean and standard error using statistical software program (SPSS for windows, version 16, USA). Difference between means of different experimental groups were carried out using one-way ANOVA with Duncan multiple comparison tests. Dissimilar superscript letters in the same column show a significance $(P>0.05)$ (Landau and Everitt, 2004).

\section{Result}

The main clinical signs observed among the E-coli infected birds were dullness, depression, raffled feathers, huddling, reduced fed and water consumption, which appeared within 24 hrs. post infection. Respiratory signs were developed 2-3 days post infection; as sneezing, rhinitis and wet eyes. As 
summarized in Table 1, mortality was highest in $\mathrm{Cl}$ group (25\%) followed by those of RI (10\%) and then the lowest percentage were recorded within $\mathrm{FI}(5 \%)$.

Table (1): The mortality percentage $(N=20)$ in chicken administrated Rosemary and Fenugreek for 6weeks and experimentally infected with E-Coli.

\begin{tabular}{|lll|}
\hline Groups & Number of dead chicks & Mortality \% \\
CN & 0 & 0 \\
$\mathrm{Cl}$ & 5 & 25 \\
$\mathrm{RI}$ & 2 & 10 \\
$\mathrm{FI}$ & 1 & 5 \\
\hline
\end{tabular}

\section{Growth Performance parameters}

$\mathrm{Cl}$ group showed a significant decline in BW and BWG compared to $\mathrm{CN}$. Meanwhile, $\mathrm{RI}$ and $\mathrm{FI}$ groups revealed a significant increase in BW and BWG compared with $\mathrm{Cl}$, with more significance in $\mathrm{FI}$ group. Moreover, non- significant change was reported in FI group compared with CN (Fig. 1A, B). Concerning FC and $\mathrm{FCR}, \mathrm{Cl}$ group showed a significant decrease when compared with $\mathrm{CN}$. Additionally, a significant decline of FC and FCR was noted among $\mathrm{Rl}$ and $\mathrm{FI}$ groups in comparison with $\mathrm{Cl}$, with the less $\mathrm{FC}$ and FCR in Rl group (Fig. 1C, B).

\section{Cholesterol and glucose levels}

Concerning cholesterol and glucose levels, $\mathrm{Cl}$ group showed a significant increase and a significant decrease in cholesterol and glucose levels, respectively when compared CN (Fig. 2A, B). RI and FI groups revealed a significant decline in cholesterol level compared with Cl (Fig. 2A). RI group showed a significant increase, while $\mathrm{Fl}$ group revealed a significant decrease in glucose level in comparison with $\mathrm{Cl}$ (Fig. 2B). RI group showed a non-significant change in glucose level when compared with CN (Fig. 2B).

\section{AST and ALT activities, UA and Cr concentrations}

As shown in figure $3, \mathrm{Cl}$ group showed a significant increase in AST and ALT activities along with a significant elevation in UA and Cr levels when compared with CN. On the other hand, both RI and FI groups showed a significant decline in their levels compared with $\mathrm{Cl}$, with the least recorded value in $\mathrm{Fl}$.

\section{Immunological profile}

Pointing to IL- 6 and IgG levels, $\mathrm{Cl}$ group revealed a significant increase in their levels compared with $\mathrm{CN}$ (Fig. 4A, B). Meanwhile, both RI and FI groups showed a significant decrease in IL-6 (Fig. 4A) when 
comaped with $\mathrm{Cl}$, along with a significant elevation in IgG level (Fig. 4B) when comapared with $\mathrm{CN}$ and $\mathrm{Cl}$ groups, with the lowest value of IL- 6 and the highest IgG level obtained from FI group.

\section{Hepatic and renal SOD activities}

Regarding hepatic and renal SOD activities, $\mathrm{Cl}$ group showed a significant decline in their levels when compared with CN. In contrary, RI and FI groups showed a significant elevation of SOD levels in comparison with $\mathrm{Cl}$ (Fig. 5). A non-significant change in hepatic and renal SOD levels was noted among $\mathrm{CN}, \mathrm{Rl}$ and FI (Fig. 5).

\section{Sera antioxidant indices}

With regard to antioxidant indices, $\mathrm{Cl}$ group revealed a non-significant decline in TAC and CAT levels compared with CN group (Fig. 6A, B). RI and FI groups showed a significant increase of TAC and CAT levels compared with $\mathrm{Cl}$ one (Fig. 6A, B). On the other hand, non-significant changes in TAC and CAT activities were recorded among RI and FI groups (Fig. 6A, B).

\section{Histopathological evaluations}

In all four treated-groups; hepatic, renal, intestinal, splenic, thymic and bursal specimens were processed further for histopathological analysis. Architectural changes were successively recorded in all selected organs of experimental broilers. The histological structures of all previously mentioned organs in response to different treatments were illustrated in figures $7,8,9,10,11$ and 12 , respectively.

The microscopical examination of hepatic tissue sections, obtained from $\mathrm{CN}$ group, demonstrated normal hepatic architecture along with normally arranged hepatocytes separated by hepatic sinusoids and radiated from the central vein. The hepatocytes appeared crowded polygonal cells with centrally located spherically basophilic nuclei and acidophilic cytoplasm (Fig. 7A). In contrast, Cl group showed thick hepatic capsule with marked degenerative changes among hepatocytes, Kupffer cell hyperplasia, mononuclear leukocytic infiltration around the central vein, evidence of marked congestion and dilatation of central vein and sinusoids as well as marked diffuse necrobiotic changes of hepatic tissue. Such degenerative changes were evidenced by vacuolar degeneration in some pyknotic hepatocytes. Moreover, fibrous connective proliferation was observed around the portal area admixed with mononuclear leukocytic infiltration (Fig. 7B). RI birds' liver revealed very mild degenerative changes in hepatocytes with mononuclear cellular infiltration. The central vein slightly dilated and congested compared to control group (Fig. 7C). Meanwhile, FI birds' liver showed near normal hepatocellular organization and architecture, with very mild degenerative changes of some hepatocytes and less mononuclear cell infiltration, others showed regeneration in the rest of the cells. Additionally, the central vein appears normal (Fig. 7D).

The selected renal sections obtained from $\mathrm{CN}$ group revealed normal renal histological structures of the glomeruli and surrounding tubules (Fig. 8A). However, infected birds showed marked degenerative changes of tubular cells and areas of mild interstitial infiltration of mononuclear leukocytic cells were 
noticed among the renal cortex of this treated group. Additionally, congestion of the renal blood vessels and inter-tubular capillaries were also observed along with extravasated RBCs among this group (Fig. 8B). The degenerative changes of tubular cells are indicated by vacuolar and hydropic degeneration. Additionally, individual epithelial cells were shrunken with pyknotic nuclei. Concerning RI birds, the kidneys showed mild congestion of the renal blood vessels and inter-tubular capillaries. Additionally, the lining epithelium of the convoluted tubules was mostly appeared degenerated (Fig. 8C). The degenerated changes of renal structures were seen to be disappeared in FI group which exhibited near normal renal features (Fig. 8D).

Control untreated birds revealed normal intestinal architecture with uniform intestinal villi lined by columnar epithelium with goblet cells in between, as well as intestinal glands located between the bases of villi in intestinal mucosal layer (Fig. 9A). Even the intestine of infected birds showed vacuolation, atrophy, sloughing and necrosis of intestinal villi along with leukocytic infiltration (mainly hetrophils, macrophage and lymphocyte) associated with edema and necrosis of the muscularis mucosa (Fig. 9B). The intestinal tissue architecture of RI birds revealed some degenerative changes of the intestinal architecture but less than that picture recorded in an infected group alone (Fig. 9C). Meanwhile, FI birds showed normal villus architecture with mild cellular infiltration in intestinal mucosa and sub-mucosa when compared with the control (Fig. 9D).

Histological examination of splenic sections obtained from $\mathrm{CN}$ broilers showed no difference in splenic architecture enclosing normal white and red pulps (Fig. 10A). Additionally, the splenic red pulp formed mainly from cords of reticular and blood cells associated with immunocompetent cells; macrophages and lymphocytes. The white pulp is the splenic lymphatic tissue, composed mainly of lymphoid follicles with periarterial sheath (Fig. 10A). Meanwhile, the infected group showed noticeable pathological changes among splenic parenchyma when compared to control group. These changes include lymphocytic depletion and degeneration (Fig. 10B). Additionally, massively congested areas within the splenic red pulp were noted. Marked increasing of the area red pulp on the expense of the white one was also recorded among this infected group. RI group showed a significant difference from that of infected birds without any treatment including relative improvement of white pulp containing small-sized lymphoid follicles with mild to moderate congestion of splenic blood vessels along red pulp (Fig. 10C). Splenic parenchyma restored its architecture to almost the normal picture and appeared to be regenerated after fenugreek treatment with mild congestion of splenic blood vessels (Fig. 10D).

The present light microscopic study of thymic sections from control untreated birds revealed thin connective tissue capsule surrounded the gland, numerous fine septa of connective tissue originated from the capsule were divided the organ into incompletely separated lobules. Each lobule organized into a peripheral cortex and a central medulla with numerous thymocytes, few macrophages, and diffuse Hassall's corpuscles found (Fig. 11A). On the other hand, the thymus of $\mathrm{Cl}$ group showed marked lymphocytic depletion when compared with the thymus of the control non-infected group along with blood vessels congestion and extravasated haemo biotic cells (Fig. 11B). Lymphocytic necrotic areas were also noted near the area of thymic cortex concomitant with an irregular arrangement of thymic cells 
within cortex and medulla. Hence, the boundaries between the cortex and medulla were mingled together. Both $\mathrm{RI}$ and FI revealed thymic architectural improvements but the best pictures were observed in the infected group treated with fenugreek (Fig. 11C, D).

It is clearly noticed that the bursal sections obtained from $\mathrm{CN}$ group showed normal longitudinal mucosal folds projected into the lumen covered by follicular epithelium, numerous follicles filled the lamina propria of each fold. Each bursal follicle was composed a peripheral cortex and a central medulla. The cortex composed mainly of many closely packed small lymphocytes meanwhile medulla contained fewer cells of various sizes (Fig. 12A). Meanwhile that of the infected bird's revealed mild to moderate lymphoid depletion with severe diffuse edema of the interfollicular connective tissue in the lamina propria (Fig. 12B). In the medulla of the follicles, some lymphocytes showed karyopy knosis. Regarding RI group, there was still tendency of interfollicular edema and mild lymphoid depletion among the examined sections (Fig. 12C), however, FI group showed an improvement of the degenerative changes when compared with infected group with less edematous area among the interfollicular connective tissue (Fig. 12D).

\section{Discussion}

The prohibition of nutritive antibiotic use in Europe, as well as the increased awareness of the consumers, triggered a need for natural and safe feed additives to achieve better poultry production. Herbal plants are used in animal nutrition as appetite, digestion stimulants, physiological functions stimulants, prevention and treatment of certain pathological conditions, and antioxidants (Mohamed et al., 2016 ${ }_{a}$; Mohamed et al., 2016 ; Ismaiel et al., 2017; Abdellatief et al., 2017; Emam et al., 2018; Farouk et al., 2020; Gad et al., 2021). The current study focused on the comparative efficacy of rosemary and fenugreek as feed additives, growth promoters, immunostimulants and tissue protective agents against $E$-Coli infection in broilers.

The decreasing effect of E-Coli infection on B.W., B.W.G, FC, and FCR, noted in the present study, may be attributed to colonizing of $E$-coli in the intestinal wall and secreting toxins so affect intestinal integrity which reflected on feed intake and so on weight gain (Gomis et al., 1997; El-Baky et al., 2014). This assumption is proved by intestinal histopathological examination where $E$-Coli badly affect intestinal tissues with atrophy, sloughing and necrosis of intestinal villi and glands along with leukocytic infiltration, which came in accordance with Moursi et al. (2008).

Moreover, the present findings indicated a decreasing of BW among RI birds compared with CN group, which came in agreement with Hernández et al. (2004); Abd El-Latif et al. (2013) and Soltani et al. (2016), this likely was due to reduction in feed intake that resulting from the strong flavor of rosemary which need an adaptation period for accommodating oral and nasal sensing, preparing the gastrointestinal tract for food reception, and modulating digestive secretions and gut motility. Additionally, it may be also due to the fact that rosemary leaves contain high crude fiber particularly, cellulose which may hampered nutrient utilization by chickens (Barelli, 2013; Soltani et al., 2016). Oppositely to the results of Mathlouthi et al. (2012) who recorded good growth performance effects of rosemary, that may be due to the 
difference in the used rosemary form, source, and concentration (Yesilbag et al., 2011). On the other hand, fenugreek cleared an elevating effect on BW and BWG, which come in agreement with Park and Kim (2015). Meanwhile, it not harmony with that results of Saki et al. (2014) and Patel et al. (2014). Our finding may be attributed to fenugreek controlling effect on potential pathogens in gut microflora, thus move the animals from immune defense stress to increase absorption of essential nutrients, improving the digestive capacity of the small intestine and thereby helping animals to grow better, as mentioned by Hashemi and Davoodi (2011). Such results clearly confirmed by histopathological evaluation that revealed less degenerative changes in RI intestine and normal villus architecture in fenugreek infected intestinal tissue. This good histological picture came in accordance with Gurkan et al. (2015).

In the current study, E-Coli infection resulted in an increase in AST, ALT, UA, Cr and cholesterol, with a decline in glucose level. These findings are in accordance with Zaki et al. (2012) and Abdel Ziz et al. (2016) who found that $E$. coli infection in chickens resulted in significant increase in liver enzymes (AST and ALT) activities. Our results also were in complete harmony with those reported by Joan and Pannel (1981), who stated that the E-Coli infection produced alteration in cellular permeability due to changes in cell membrane which allows the escape of these enzymes into serum in abnormal high level. Our findings are magnified by histopathological examination of hepatic and renal tissues which expressed as hepatocytic vacuolar degeneration and marked necrobiotic changes of hepatic tissue, along with renal tubular degenerative changes. This histopathological figures came in agreement with Moursi et al. ( 2008).

On contrary, rosemary succeed to decrease AST, ALT, UA and Cr levels, which was proved by histopathological examination that revealed mild degenerative changes in hepatocytes. Similar data obtained by Albasha and Azab (2014); Mohamed et al. (2016a) who recorded the protective effect of rosemary supplementation against cadmium, gentamicin and lead acetate induced hepatorenal toxicity, respectively. Azab et al. (2016) related the hepatoprotective effect of rosemary to its principal antioxidant constituents (rosmarinic acid, diterpenoids such as carnosic acid, carnosol, carotenoid and alphatocopherol) which inhibit free radicals' generations. Also Mohamed et al., (2016a) related the renal protecting effect of rosemary to synergistic interactions between its individual components with his antioxidant properties. Moreover, rosemary showed hypercholesteremic properties in RI group, which also recorded by Ghazalah and Ali (2008); Polat et al., (2011), who related it to leaves defatted portion rich in fibrous content that preventing intestinal cholesterol absorption. Additionally, fenugreek mediated a decrease of AST, ALT, UA, $\mathrm{Cr}$ and glucose levels than $\mathrm{Cl}$, which magnified by histopathological examination that revealed near normal hepatocellular and renal architecture. These results also recorded by Mamoun et al. (2014); Park and Kim (2015). Mentreddy (2007) who related hypoglycemic effect of fenugreek to the steroidal saponins, alkaloids and 4-hydroxy-isoleucine soluble dietary fiber fraction, exerting delaying effect on sucrose digestion and inhibition of carbohydrate hydrolyzing enzyme, as well as stimulating insulin secretion from the $\beta$ pancreatic cells.

Our findings of increased IgG and IL- 6 levels in Cl group, besides came in accordance with (Eleiwa et al., 2011). The microbial pathogens stimulate the immune responses which produce cytokine IL-6, favor B- 
cell maturation and produce neutralizing antibodies IgG that neutralize bacterial toxins (D'Elios et al., 2011). Since, the efficacy of immune system in chickens mainly depends on the bursa of fabricius and thymus for lymphocytic differentiation and initiating humeral and cellular-immune responses. So the marked bursal and thymic lymphocytic depletion, induced by E.coli experimental infection, was previously reported by Madian et al. (2008) who reported an immunosuppressive effect of E-coli. Meanwhile, Nakamura et al. (1986) related this depletion to a combination of direct effects of E-colitoxic components and non-specific stress factors.

Generally, herbs rich of flavonoids, vitamin C, and carotenoids benefits the immune system, and presenting immunostimulant effect through; enhanced phagocytic activity, modulation of cytokine secretion, histamine release, immunoglobulin secretion, plasma myeloperoxidase and lysozyme activity increase (Mirzaei-Aghsaghali, 2012). Rosemary abled to increase IgG, decrease IL-6 in RI birds, these results are agreed with Da Rosa et al., (2013) who related its anti-inflammatory activity to effect on decreasing the proinflammatory cytokines with increasing of the anti-inflammatory cytokine in mice suffered from pleurisy. Additionally, fenugreek succeeded to increase IgG, and decrease IL-6 in FI group, this immunostimulant effects is related to high total phenolic content following both fenugreek gastric and duodenal digestion (Jayawardena et al. 2015).

E-coli endotoxin resulted in elevating the systemic cytokines (TNF and IL-6), which enhance production of superoxide anion, release of lysozyme, $\mathrm{H}_{2} \mathrm{O}_{2}$ and chemotaxis, as an adaptive mechanism to decrease reactive oxygen formation, besides increasing its uptake, resulting in the production of potent oxidant bactericidal agents (Dutta and Bishayi, 2009). Meanwhile, when the stress is too high, antioxidant activity is decreased and apoptosis is activated (Surai, 2015), which cleared the decrease in the SOD, CAT and TAC levels in our E-Coli infected group. Generally, antioxidant supplementation resulted in increased interleukin levels, elevated total lymphocytes, increased killer cell activity and antibody response to antigen stimulation. Moreover, using of antioxidants herbs in broiler feed is not important only for their health, but also for the oxidative stability of their meat products (Fellgenber and Speisky, 2006).

Rosemary can elevate the SOD, CAT and TAC in RI birds. Soltani et al. (2016) related the antioxidant properties of rosemary to the high polyphenols containing hydroxyl groups that probably stop free radical formation. Furthermore, Polat et al. (2011) observed the greatest activity of SOD through broiler supplementation of rosemary in comparison to vitamin E. Moreover, fenugreek abled to suppress oxidative stress indicated by the increase in SOD, CAT, and TAC level in FI birds. Maharana and Dadhich (2016) related these findings to the oxidative stress suppression, reduction in cell apoptosis, and fibrosis to trigonelline present in fenugreek. Additionally, Mohammadzadeh et al. (2015) recorded an elevation of catalase enzymes activities after treating rats with acetaminophen-liver toxicity by fenugreek.

\section{Conclusion}

Considering the obtained findings, it can be concluded that rosemary or fenugreek supplementation is beneficial in reduce and improve the biochemical and histological alterations induced by $E$. coli-infection 
in broilers. However, the present study suggests the protective, anti-inflammatory, antioxidant, and immunomodulatory effects of rosemary or fenugreek on E. coli-induced toxicity; the most protective efficacy was recorded in infected chicks treated with fenugreek. Moreover, the using of fenugreek as feed additive may be a good strategy against oxidative stress induced by $E$. coli, knowing that it is prohibited to administer in case of hypoglycemia. To strengthen these findings, further investigations are needed to explore the mechanism action of rosemary and/or fenugreek against $E$. coli toxicity in broilers.

\section{Declarations}

\section{Ethics approval and consent to participate}

The current scientific research scenario was considered and approved by Committee Research Ethics Board at Faculty of Veterinary Medicine, Suez Canal University, Ismailia, Egypt.

\section{Availability of data and materials}

All data generated or analyzed during this study are included in this article.

\section{Consent for publication}

Not applicable

\section{Competing interests}

The authors have no conflict of interest.

\section{Funding}

This study was self-funded by authors.

\section{Author's Contribution}

Sameh M. Farouk, Haidy G. Abd-El-Rahman, Osama A. Abdallah and Nashwa G. EL-Behidy contributed equally to the design and implementation of the research, to the analysis and discussion of the results.

\section{References}

1. Abd El-Latif A, Saleh NS, Tamer SA, Ghazy E (2013) The effects of Rosemary (Rosemarinus afficinalis) and Garlic (Allium sativum) essential oils on performance, hematological, biochemical and immunological parameters of broiler chickens. British Journal of Poultry Sciences 2(2): 16-24

2. Abdellatief SA, Galal AAA, Farouk SM, Abdel-Daim MM (2017) Ameliorative effect of parsley oil on cisplatin-induced hepato-cardiotoxicity: a biochemical, histopathological, and immunohistochemical study. Biomed Pharmacother 86:482-491 
3. Abdel Ziz, SA, AbdelMotaal SMA, Abd-allah OE, Sarhan M (2016) Concurrent use of ciprofloxacin and metronidazole for controlling of some bacterial infections in broiler chickens. Benha Vetrerinary Medical Journal 31(2): 83-92

4. Ahmadiani A, Javan M, Semnanian S, Bharat E, Kamalinejad M (2001) Anti-inflammatory and antipyretic effects of Trigonella foenum-graecum leaves extract in the rat. J Ethnopharmacol, 75, 283-286

5. Albasha MO, Azab AES (2014) Effect of cadmium on the liver and amelioration by aqueous extracts of fenugreek seeds,rosemary, and cinnamon in guinea pigs: histological and biochemical study. Cell Biology 2(2): 7-17

6. Al-Kassie G, Abd-Al-Jaleel R (2011) The effect of a mixture of anise and rosemary on broiler performance. Agriculture and Biology Journal of North America 2(9):1279-1282

7. Allain CC, Poon LS, Chan CSG, Richmond W, Fu PC (1974) Enzymatic Determination of Total Serum Cholesterol. Clin Chem 20(4): 470-475

8. Amin A, Alkaabi A, Al-Falasi S, Daoud SA (2005) Chemopreventive activities of Trigonella foenumgraecum (fenugreek) against breast cancer. Cell Biol Int 29, 687-694

9. Asai T, Masani K, Sato C, Hiki M, Usui M, Baba K, Ozawa M, Harada K, Aoki H, Sawada T (2011) Phylogenetic groups and cephalosporin resistance genes of Escherichia coli from diseased foodproducing animals in Japan. Acta Vet Scand 53:52

10. Azab AE, Albasha MO, Elsayed ASI (2016) Prevention of hepatotoxicity with curcuma longa and rosemarinus officinalis in gentamicin treated guinea Pigs. Indo American Journal of Pharmaceutical Research 6(3): 1746-1751

11. Barelli S (2013) Essential Oils in Veterinary Use: A Survey of Recent Data of the Last Decade. Universitat Wien 1-72

12. Basch E, Ulbricht C, Kuo G, Szapary P, Smith M (2003) Therapeutic applications of fenugreek. Altern Med Rev 8, 20-27

13. Benayad Z, Gómez-Cordovés C, Es-Safi NE (2014) Characterization of Flavonoid Glycosides from Fenugreek (Trigonella foenum-graecum) Crude Seeds by HPLC-DAD-ESI/MS Analysis. International Journal of Molecular Sciences 15(11):20668-85

14. Crowley LV (1967) The Reitman-Frankel colorimetric transaminase procedure in suspected myocardial infarction. Clinical Chemistry 13(6): 482-487

15. Da Rosa JS, Facchin BM, Bastos J, Siqueira MA, Micke GA, Dalmarco EM, Frödev TS (2013) Systemic administration of rosmarinus officinalis attenuates the inflammatory response induced by carrageenan in the mouse model of pleurisy. Planta Medica 79(17): 1605-1614

16. D'Elios MM, Benagiano M, Bella CD, Amede A (2011) T-cell response to bacterial agents. The Journal of Infection in Developing Countries 5(9): 640-645

17. Demir E, Sarica S, Özcan MA, Suiçmez M (2003) The use of natural feed additives as alternatives for an antibiotic growth promoter in broiler diets. British Poultry Science 44, 44-45 
18. Djeridane A, Yousfi M, Nadjemi B, Boutassouna D, Stocker P, Vidal N (2006) Antioxidant activity of some algerian medicinal plants extracts containing phenolic compounds. Food Chem 97, 654-660

19. Dutta K, Bishayi B (2009) Escherichia coli lipopolysaccharide administration alters antioxidant profile during hypercholesterolemia. Indian Journal of Clinical Biochemistry 24(2): 179-183

20. El-Baky AAA, Mohamed AH, Bashandy M, Awaad MH (2014) Clinicopathological and immunological studies on pediococcus acidilactici in chickens. Journal of the Egyptian Veterinary Medical Association 74(5): 889-910

21. El-Boshy MS, Header EA, ElSawy NA, Basalamah MB, Mubarak MS et al. (2015) Studies on the Constituents of Rosmarinus officinalis and Their Synergistic Effect in Experimental Diabetic Rats. $J$ Invest Biochem 4(1), 36-43

22. Elbushra ME (2012) Effect of Dietary Fenugreek Seeds (Trigonella foenum) as Natural Feed Addition on Broiler Chicks Performance. Journal of Science and Technology Agricultures and Vetrinary Sciences (JAVS NO.2): 13(2)

23. Eleiwa NZ, El Sayed EM, Nazim AA (2011) Prophylactic and therapeutic evaluation of the phytobiotic (Orego-stim) ${ }^{\circledR}$ in chicken experimentally infected with E. coli. Journal of American Science 7(8): 91 102

24. Emam MA, Farouk SM, Abdo M (2018) The Ameliorative Potential of Probiotics and/or Silymarin on Thioacetamide Induced Hepatotoxicity in Rats: Histological and Immunohistochemical Study. Int J Morphol 36(2):661-669

25. Farouk SM, Gad FA, Emam MA (2020) Comparative immuno-modulatory effects of basil and sesame seed oils against diazinon-induced toxicity in rats; a focus on TNF-a immunolocalization. Environmental Science and Pollution Research. https://doi.org/10.1007/s11356-020-10840-x

26. Fellgenber MA, Speisky H (2006) Antioxidants:their effects on broiler oxidative stress and its meat oxidative stability. World Poultry Science Journal 62: 53-70

27. Fossati P, Prencipe L, Berti G (1980) Use of 3,5-dichloro-2-hydroxybenzenesulfonic acid/4aminophenazone chromogenic system in direct enzymic assay of uric acid in serum and urine. Clinical Chemistry 26(2): 227-231

28. Gad FA, Farouk SM, Emam MA (2021) Antiapoptotic and antioxidant capacity of phytochemicals from Roselle (Hibiscus sabdariffa) and their potential effects on monosodium glutamate-induced testicular damage in rat. Environmental Science and Pollution Research. Environmental Science and Pollution Research 28:2379-2390

29. Genena AK, Hense H, Smânia Junior A, Souza SM (2008) Rosemary (Rosmarinus officinalis): a study of the composition, antioxidant and antimicrobial activities of extracts obtained with supercritical carbon dioxide. Ciência E Tecnologia de Alimentos 28(2): 463-469

30. Ghazalah AA, Ali AM (2008) Rosemary leaves as a dietary supplement for growth in broiler chickens. International Journal of Poultry Science 7(3): 234-239

31. Ghozlan SA, El-Far AH, Sadek KM, Abourawash AA, Abdel-Latif MA (2017) Effect of Rosemary (Rosmarinus Officinalis) Dietary Supplementation in Broiler Chickens Concerning immunity, 
Antioxidant Status, and Performance. AJVS 55 (1):152-161

32. Gomis SM, Watts T, Riddell C, Potter AA, Allan BJ (1997) Experimental reproduction of Escherichia coli cellulitis and septicemia in broiler chickens. Avian Dis 41(1): 234-240

33. Gurkan M, Yilmaz S, Kaya H, Ergun S, Alkan S (2015) Influence of three spice powders on the survival and histopathology of Oreochromis mossambicus before and after Streptococcus iniae infection. Marine Science and Technology Bulletin 30(4): 994-1000

34. Hariane M, Moya H (2015) A comprehensive study of the use of Cu(I)/4,4-Dicarboxy-2,2-biquinoline complexes to measure the total reducing capacity: Application in herbal extracts. Molecules 20(12): $22411-22421$

35. Hashemi SR, Davoodi H (2011) Herbal plants and their derivatives as growth and health promoters in animal nutrition. Veterinary Research Communications 35(3): 169-180

36. Hernández F, Madrid J, García V, Orengo J, Megías MD (2004) Influence of two plant extracts on broilers performance, digestibility, and digestive organ size. Poultry Science 83(2): 169-174

37. Ibarra A, Cases J, Bily A, He K, Bai N, Roller M, Coussaert A, Ripoll C (2010) Importance of Extract Standardization and In Vitro/Ex Vivo Assay Selection for the Evaluation of Antioxidant Activity of Botanicals: A Case Study on Three Rosmarinus officinalis L. Extracts. Journal of Medicinal Food, 13(5) 1167- 1175

38. Ismaiel SI, Farouk SM, El-Ramady RA, Khalil WF (2017) Ameliorative Impacts of Tribulus terrestris Against Ivermectin-Induced Hepato-Renal Toxicity in Rabbit: Pharmacological and Histopathological Study. American Journal of Animal and Veterinary Sciences 12 (1):8-16

39. Jayawardena N, Watawana MI, Jayathilaka RT, Waisundara VY (2015) Evaluation of the Total Antioxidant Capacity, Polyphenol Contents and Starch Hydrolase Inhibitory Activity of Ten Edible Plants in an In vitro Model of Digestion. Evidence-Based Complementary and Alternative Medicine 70(1): 71-76

40. Joan F, Pannel P (1981) Clinical chemistry in diagnosis and treatment, 3rd ed. Llayed-luke, London

41. Khan IA, Abourashed E (2010) Leungs Encyclopedia of Common Natural Ingredients used in Food, Drugs and Cosmetics (3nd Edition). Carbohydrate Polymers (Vol. 58). Hoboken, New Jersey.: John Wiley and Sons, Inc

42. Kavirasan S, Naik GH, Gangabhagirathi R, Anuradha CV, Priyadarsini KI (2007) In vitro studies on antiradical and antioxidant activities of fenugreek (Trigonella foenum-graecum) seeds. Food Chem $103,31-37$

43. Kenny O, Smyth TJ, Hewage CM, Brunton NP (2013) Antioxidant properties and quantitative UPLCMS analysis of phenolic compounds from extracts of fenugreek (Trigonella foenum-graecum) seeds and bitter melon (Momordica charantia) fruit. Food Chem 141, 4295-4302

44. Kinoshita T, Hiraga Y, Nakamura N, Kiajo A, linuma F (1979) determention of glucose in blood using glucose oxidase -peroxidase system and 8 hydroxyquinoine -p-anisidine.Chemical pharma and bulltein 27(2): 568-570 
45. Koivunen ME, Krogsrud RL (2006) Principles of Immunochemical Techniques Used in Clinical Laboratories. Laboratory Medicine 37(8): 490-497

46. Landau S, Everitt B (2004) A handbook of statistical analyses using SPSS. Statistics in Medicine (Vol. 24)

47. Lau GL, Sieo CC, Tan WS, Hair-Bejo M, Jalila A,Ho YW (2010) Efficacy of a bacteriophage isolated from chickens as a therapeutic agent for colibacillosis in broiler chickens. Poult Sci 89:2589-2596

48. Madian K, El-Ghany WAA, Kamel GM (2008) Efficacy of pefloxacin for the treatment of broiler chickens experimentally infected with Escherichia coli 078: K 80. Proceeding of the 3rd Scientific Congress of the Egyptian Society for Animal Management. October, 28th - 29th, 94-105

49. Maharana L, Dadhich OP (2016) Review on role of herbal drug in the prevention and managment of kidney disease. An International Journal of Research in AYUSH and Allied Systems 3(1): 500-508

50. Maiorano G, Stadnicka K, Tavaniello S, Abiuso C, Bogucka A, Bednarczyk M (2016) In ovo validation model to assess the efficacy of commercial prebiotics in enhancing broiler performance and reducing lipid oxidation of meat. Poultry Science 96(2): 1-8

51. Majo N, Gibert X, Vilafranca M, Loan CJO, Allan GM, Costa L, Ramis A (1997) Turkey rhinotracheitis virus and Escherichia coli experimental infection in chickens: histopathological, immunocytochemical and microbiological study. Veterinary Microbiology 135(57): 29-40

52. Mamoun T, Mukhtar MA, Tabidi MH (2014) Effect of Fenugreek Seed Powder on the Performance, Carcass Characteristics and Some Blood Serum Attributes. Advance Research in Agriculture and Veterinary Science 1(1): 6-11

53. Mathlouthi N, Bouzaienne T, Oueslati I, Recoquillay F, Hamdi M, Urdaci M, Bergaoui R (2012) Use of rosemary, oregano, and a commercial blend of essential oils in broiler chickens: In vitro antimicrobial activities and effects on growth performance. Journal of Animal Science 90(3): 813-823

54. Meghwal M, Goswami TK (2012) A review on the functional properties, nutritional content, medicinal utilization and potential application of Fenugreek. Journal of Food Processing Technology 3(9): 110

55. Mentreddy SR (2007) Medicinal plant species with potential antidiabetic properties. Journal of the Science of Food and Agriculture 87: 743-750

56. Mirzaei-Aghsaghali A (2012) Importance of medical herbs in animal feeding: A review. Annals of Biological Research 3(2): 918-923

57. Mohamed WAM, Abd-Elhakim YM, Farouk SM, $\left(2016_{a}\right)$ Protective effects of ethanolic extract of rosemary against lead-induced hepatorenal damage in rabbits. Experimental and Toxicologic Pathology 68 (8):451- 461

58. Mohamed WAM, Ismail T, Farouk SM (2016b) The ameliorative potential of ethanolic extract of propolis on hematotoxicity and structural neuronal damage in hyperthermia-exposed rats. Iranian Journal of Basic Medical Sciences 19 (8): 875 - 882 
59. Mohammadzadeh A, Gol A, Oloumi H (2015) The Effects of fenugreek seed powder on oxidant and antioxidant factors in male rats with acetaminophen-induced liver toxicity. J Babol Univ Med Sci, 17: $44-51$

60. Moursi MK, Gharieb, El-genaidy (2008) Pathological and Immunological Studies on Dietary T-2 Toxin with Concurrent E. coli Infection in Chickens and Some Relevant Control Trial. SCVMJ, XIII, (2): 565602

61. Nakamura K, Imada Y, Maeda M (1986) Lymphocytic depletion of bursa of Fabricius and thymus in chickens inoculated with Escherichia coli. Veterinary Pathology 23(6): 712- 717

62. Nobo G, Moreki JC, Nsoso, SJ (2012) Feed intake, body weight, average daily gain, feed conversion ratio and carcass characteristics of helmeted guinea fowl fed varying levels of Phane meal (Imbrasia belina) as replacement of fishmeal under intensive system. International Journal of Poultry Science 11(6): 378-384

63. Owen J, Iggo B, Scandrett FJ, Stewart CP (1954) The determination of creatinine in plasma or serum, and in urine; a critical examination. The Biochemical Journal 58(3): 426-437

64. Park JHA, Kim IHA (2015) Interactive effects of fenugreek (Trigonella foenum-graecum L.) seed extract supplementation and dietary metabolisable energy levels on the growth performance, total tract digestibility, blood profiles, and excreta gas emission in broiler chicken. Animal Production Science 56(10):1677-1682

65. Patel RM, Garg DD, Patel VR, Vahora SG, Katariya MA, Choubey M (2014) Effect of dietary supplementation of garlic (Allium sativum) and fenugreek (Trigonella foenum-graecum L.) seed powder on growth performance and blood biochemical parameters in broilers. Indian Journal of Poultry Science 49(1): 17-20

66. Petit P, Sauvaire Y, Ponsin G, Manteghetti M, Fave A, Ribes G (1993) Effect of a fenugreek seed extraction on feeding behaviour in the rat: Metabolic-endocrine correlates. Pharmacol Biochem Behav 45, 369-374

67. Petropoulos GA (2002) Fenugreek-The Genus Trigonella; Taylor and Francis: London, UK; New York, NY, USA, 1-255

68. Polat U, Yesilbag D, Eren M (2011) Serum Biochemical Profile of Broiler Chickens Fed Diets Containing Rosemary and Rosemary Volatile Oil. J BIOL ENVIRON SCI 5(13): 23-30

69. Rajalakshmi R, Nanavaty K, Gumashta A (1964) Effect of cooking procedures on the free and total niacin content of certain food. J Nutr Diet 1: 276-280

70. Saki AA, Kalantar M, Rahmatnejad E, Mirzaaghatabar F (2014) Health Characteristics and Performance of Broiler Chicks in Response to Trigonella foenum graecum and Foeniculum vulgare. Iranian Journal of Applied Animal Science 4(2): 387-391

71. Sarica S, Ciftci A, Demir E, Kilinc K, Yildirim Y (2007) Use of an antibiotic growth promoter and two herbal natural feed additives with and without exogenous enzymes in wheat-based broiler diets. S Af J Anim Sci 35(1): 61-72 
72. Shang M, Cais Han J, Li J, Zhao Y, Zheng J, Namba T, Kadota S, Tezuka Y, Fan W (1998) Studies on flavonoids from fenugreek (Trigonella foenum graecum L). Zhongguo Zhong Yao Za Zhi, 23, 614639

73. Sharma RD, Raghuram TC, Rao NS (1990) Effect of fenugreek seeds on blood glucose and serum lipids in type I diabetes. Eur J Clin Nutr 44, 301-306

74. Snehlata H, Dande P (2012) Trigonella foenum-graecum. Nternational Journal of Current Pharmaceutical Review and Research 2(4): 170-187

75. Soltani M, Tabeidian SA, Ghalamkari G, Adeljoo AH, Mohammadrezaei M, Fosoul SSAS (2016) Effect of dietary extract and dried areal parts of Rosmarinus officinalis on performance, immune responses and total serum antioxidant activity in broiler chicks. Asian Pacific Journal of Tropical Disease 6 (3): $218-222$

76. Srinivasan K (2006) Fenugreek (Trigonella foenum-graecum): A review of health beneficial physiological effects. Food Rev Int 22, 203-224

77. Stark A, Madar Z (1993) The effect of an ethanol extract derived from fenugreek (Trigonella foenumgraecum) on bile acid absorption and cholecterol levels in rats. Br J Nutr 69, 277-287

78. Sujapandian R, Anuradha VV, Viswanathan P (2002) Gastroprotective effect of fenugreek seeds (Trigonella foenum-graecum) on experimental gastric ulcer in rats. J Ethnopharmacl 81, 393-397

79. Surai PF (2015) Antioxidant systems in poultry biology: superoxide dismutase. Animal Nutrition 1: $1-17$

80. Suvarna SK, Layton C, Bancroft JD (2012) Bancroft's theory and practice of histological techniques book. citeulike.org

81. Taylor WG, Zaman MS, Mir Z, Mir PS, Achary SN, Mears GJ, Elder JL (1997) Analysis of steroidal sapogenins from amber fenugreek (Trigonella foenum-graecum) by capillary gas chromatography and combined gas chromatography/mass spectrometry. J. Agric. Food Chem 45, 753-759

82. Wheeler C, Salzman JA, Elsayed NM, Omaye ST, and Korte Jr DW (1990): Automated assays for superoxide dismutase, catalase, glutathione peroxidase, and glutathione reductase activity. Analytical Biochemistry 184(2): 193-9

83. Yesilbag D, Eren M, Agel H, Kovanlikaya A, Balci F (2011) Effects of dietary rosemary, rosemary volatile oil and vitamin E on broiler performance, meat quality and serum SOD activity. British Poultry Science 52(4): 472-482

84. Zaki MS, Fawzy O, Osfor MH (2012) Effect of E. coli $0 \mathrm{H} 157$ on baladi broiler chicken and some biochemical studies. Life Science Journal 9(1): 91-94

85. Zia T, Hasnain SN, Hasan SK (2001) Evaluation of the oral hypoglycaemic effect of Trigonella foenum-graecum $L$ in normal mice. J Ethnopharmacol 75, 191-195

\section{Figures}




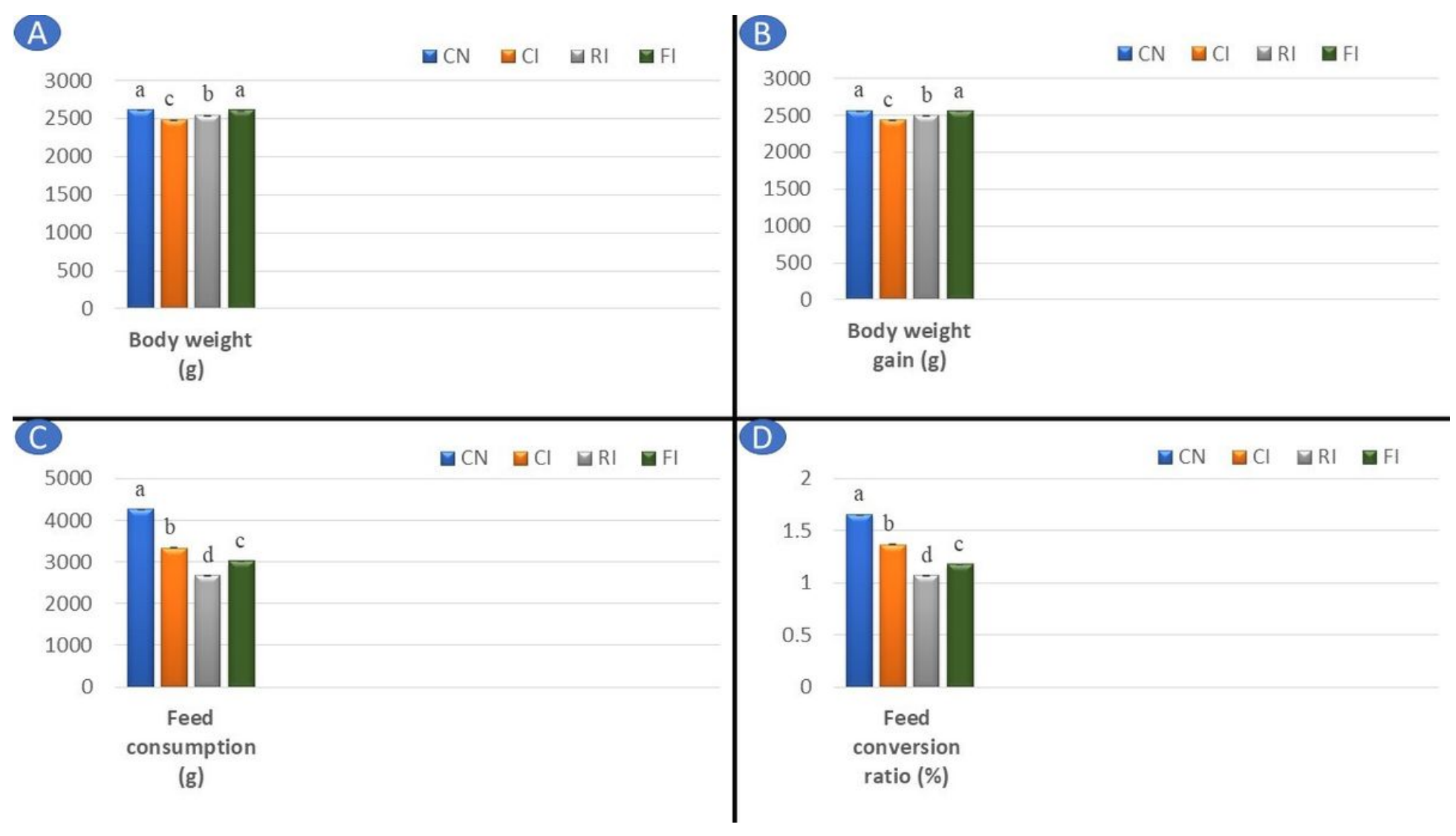

\section{Figure 1}

Mean \pm SE of body weight (A), body weight gain (B), feed consumption (C) and feed conversion ratio (D) in all experimental groups.

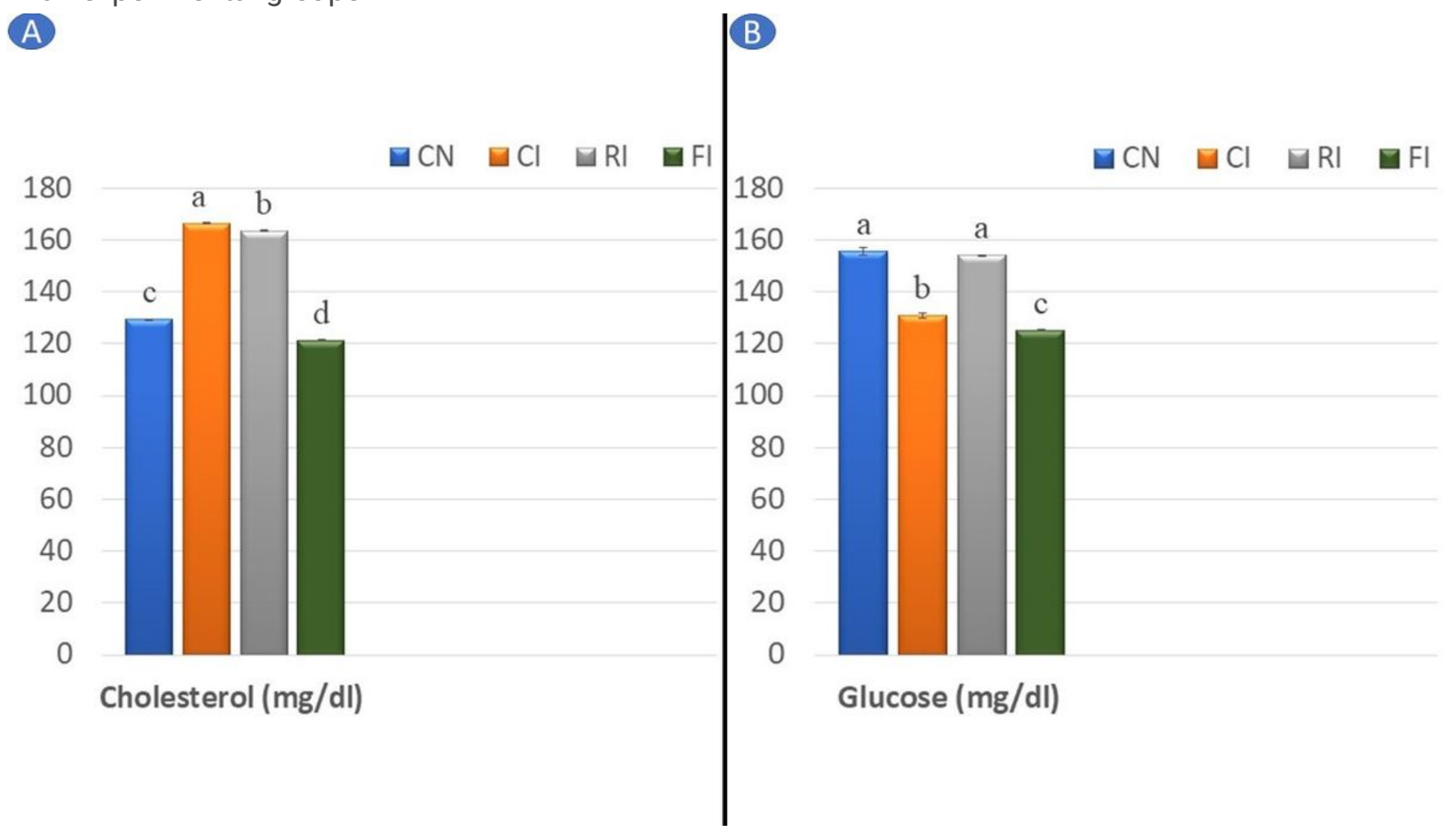


Figure 2

Mean \pm SE of cholesterol (A) and glucose (B) levels in all experimental groups.

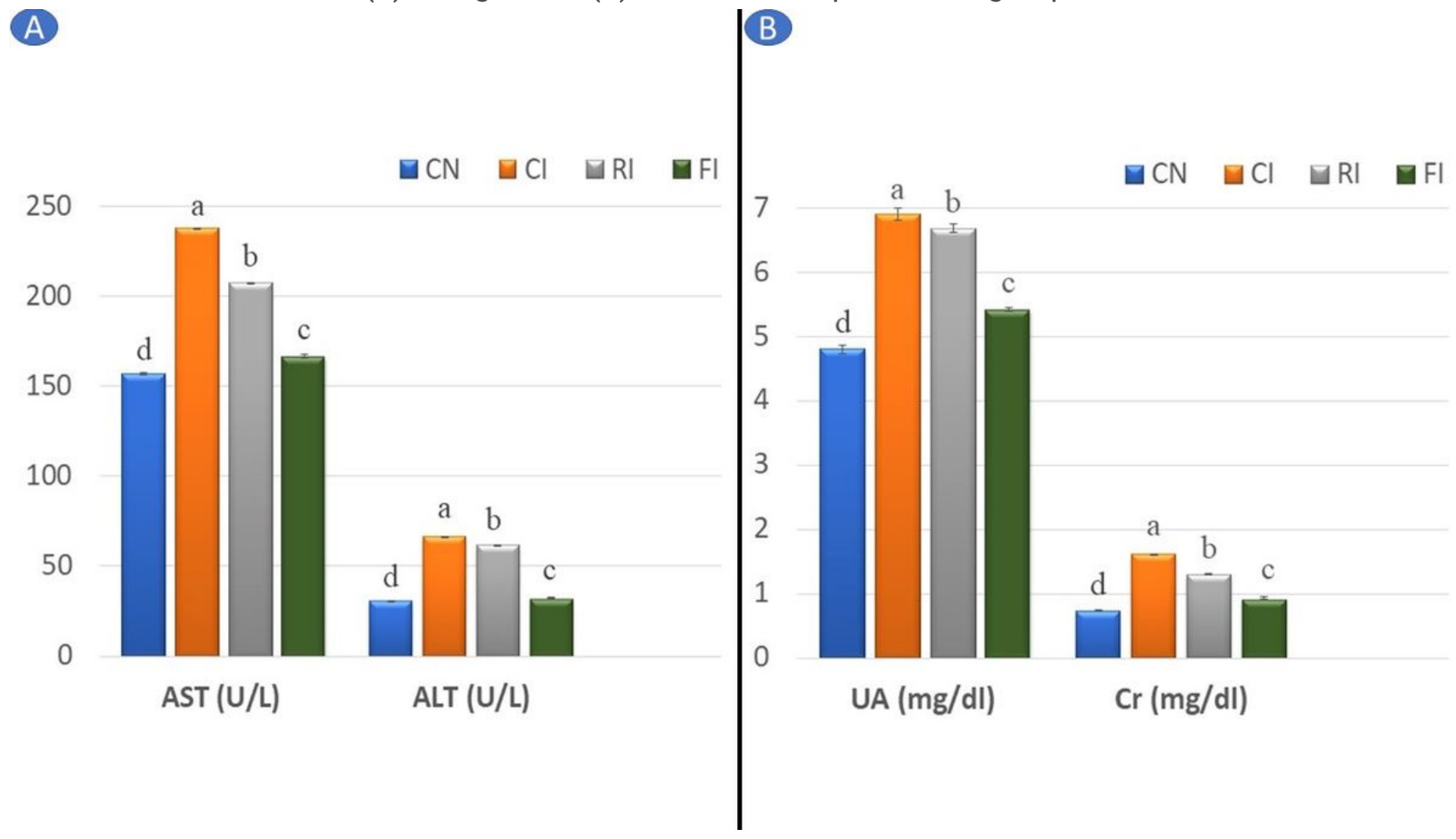

Figure 3

Mean \pm SE of AST and ALT activities (A), and UA and Cr levels (B) in all experimental groups. 


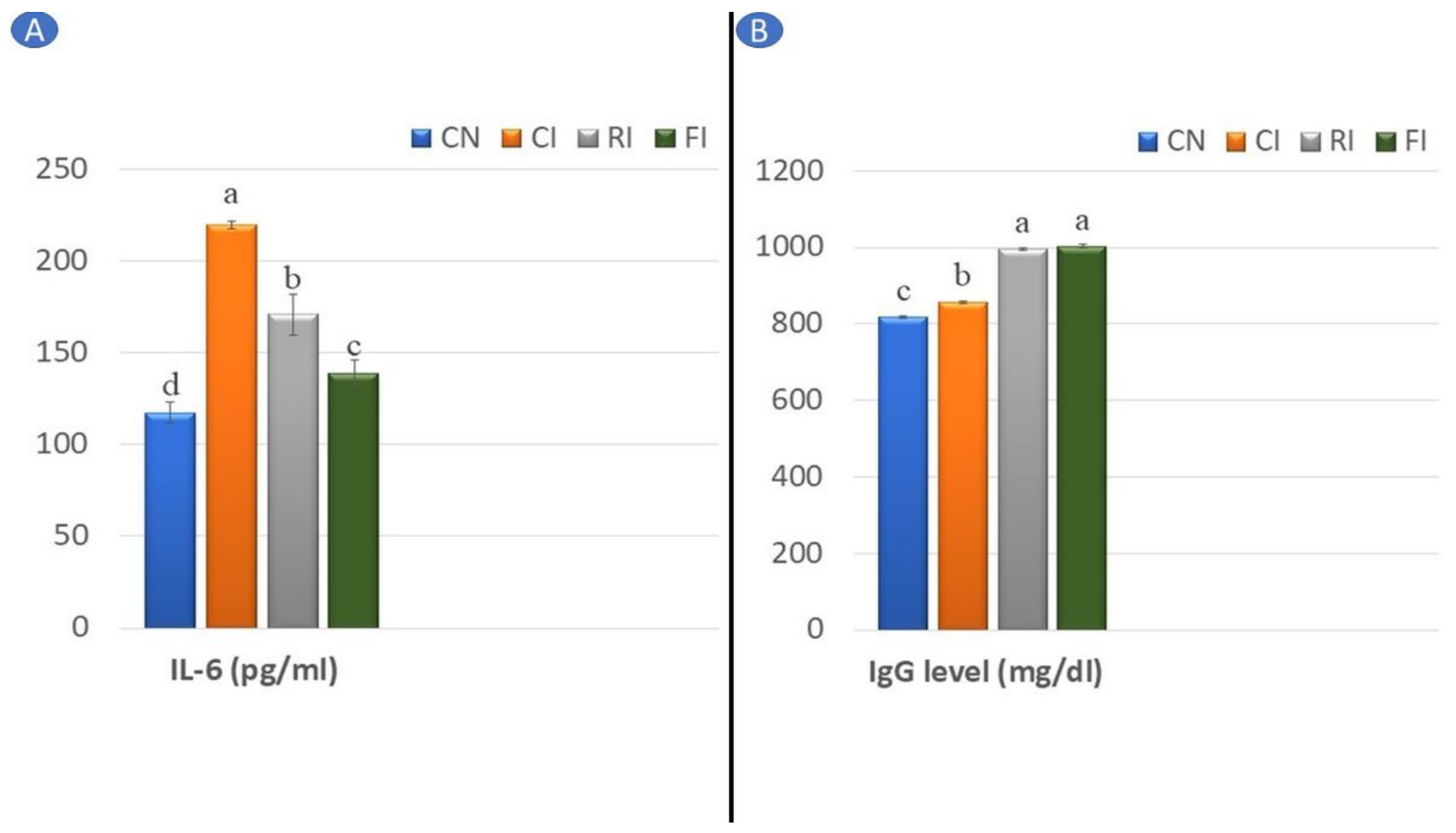

\section{Figure 4}

Mean \pm SE of IL-6 (A) and IgG (B) levels in all experimental groups.

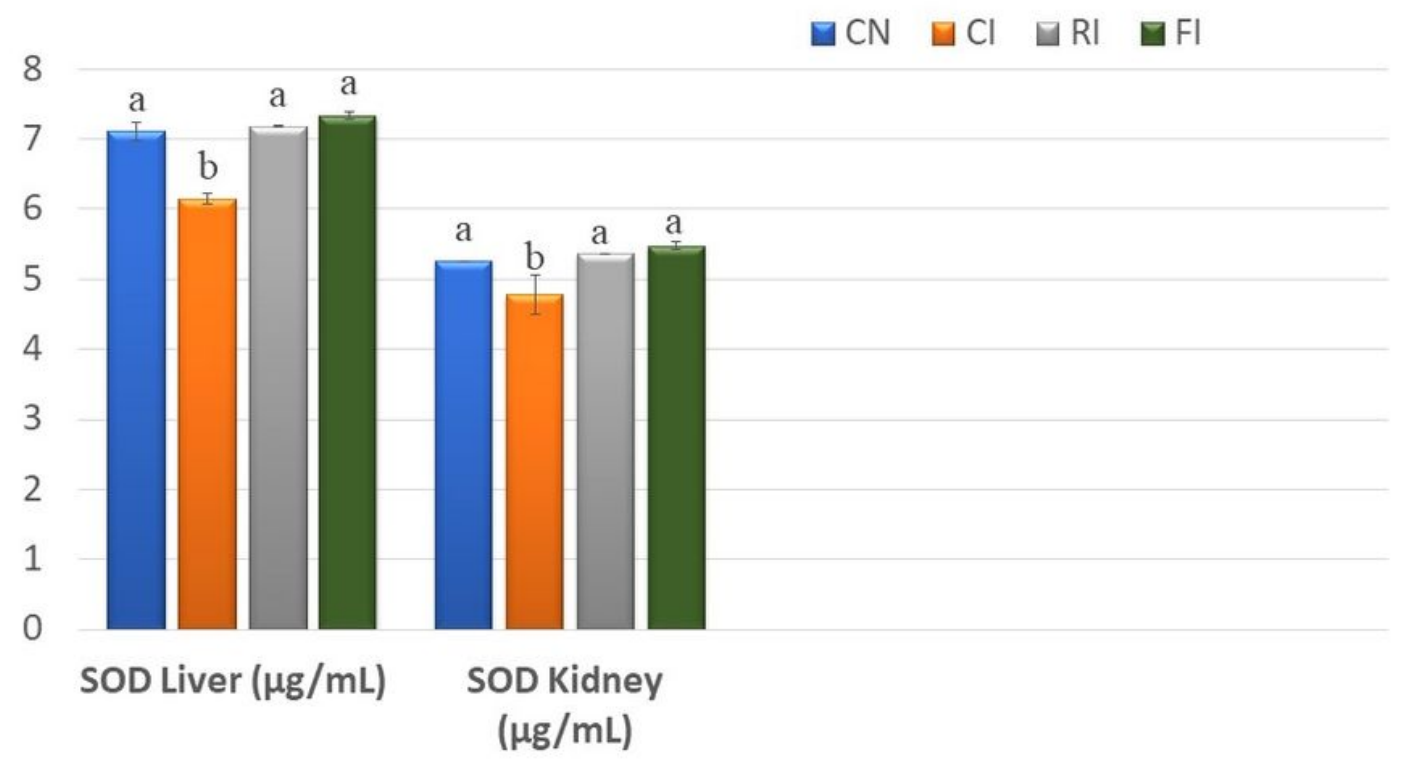


Figure 5

Mean \pm SE of SOD in hepatic and renal tissues of all experimental groups.

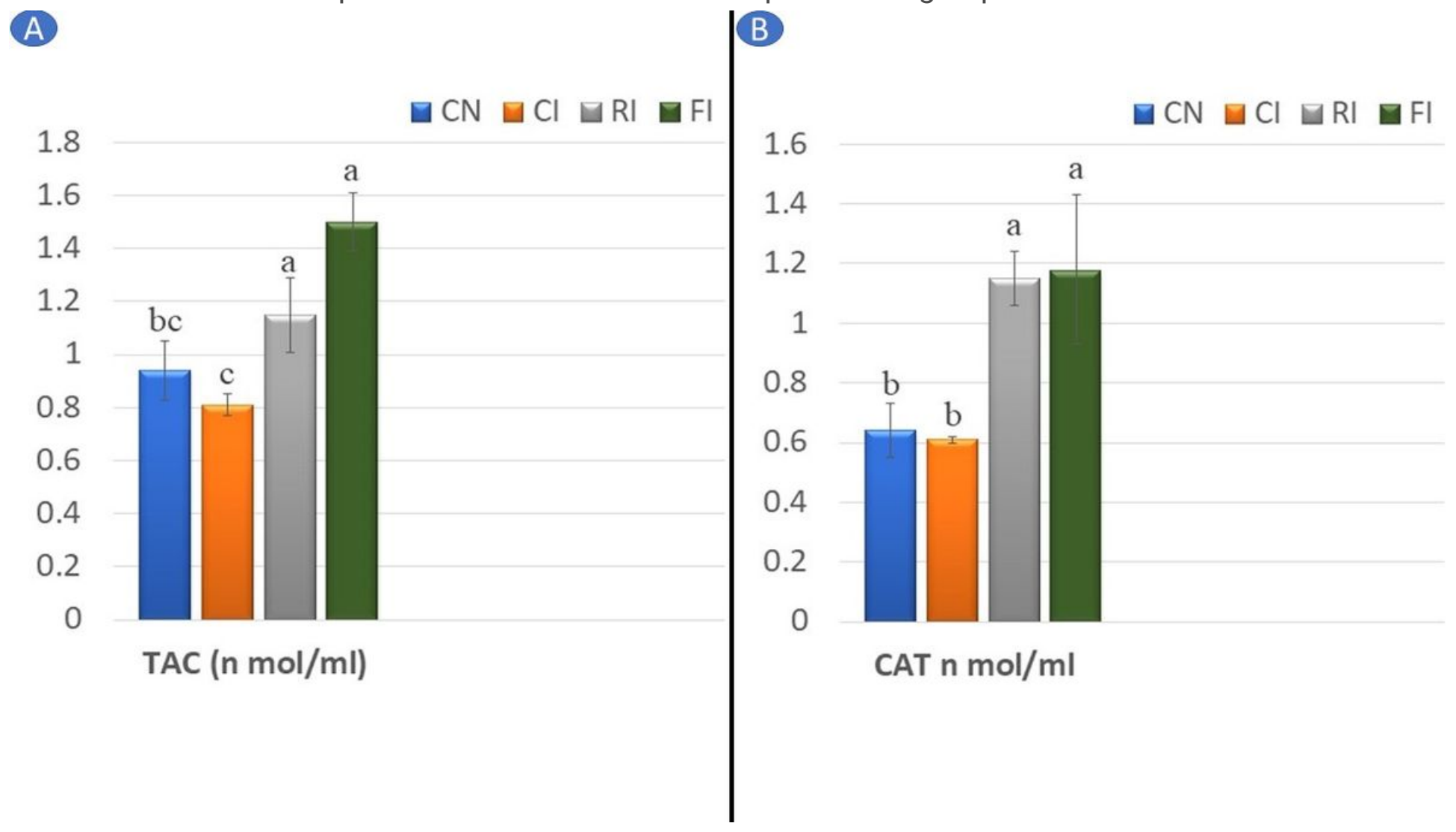

Figure 6

Mean \pm SE of TAC (A) and CAT (B) levels in all experimental groups. 

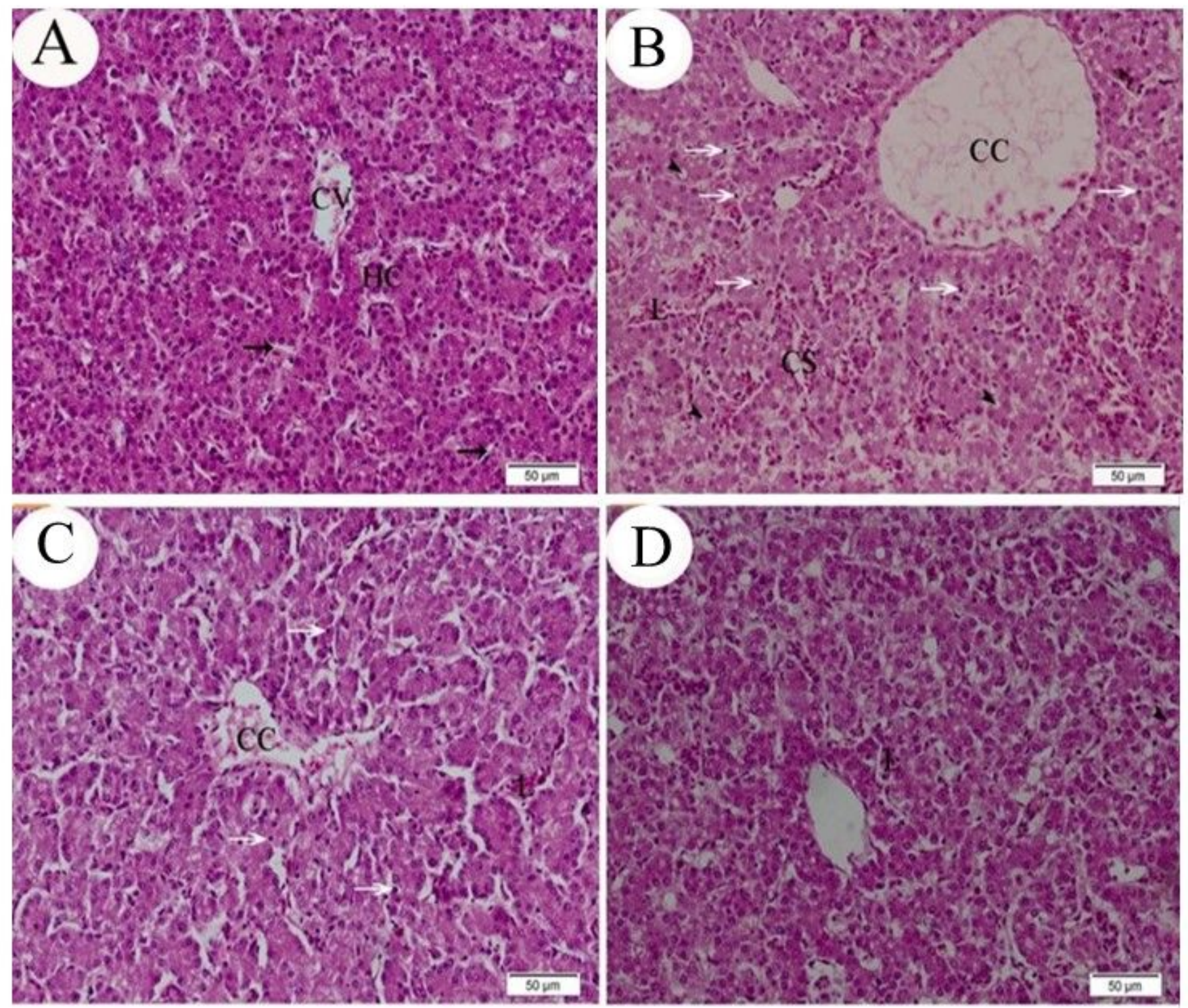

\section{Figure 7}

Representative photomicrograph of broiler liver. A; CN group, B; Cl group, C; RI group and D; FI group. Here, Hepatocytes (HC) radiated from central vein (CV); Hepatic sinusoids (thin black arrows); vacuolar degeneration in some pyknotic hepatocytes (head arrows); Kupffer cell hyperplasia (thin white arrowheads); Evidence of marked congestion and dilatation of central vein (CC) and hepatic sinusoids (CS) along with Leukocytic infiltration (L). H\&E stain. 

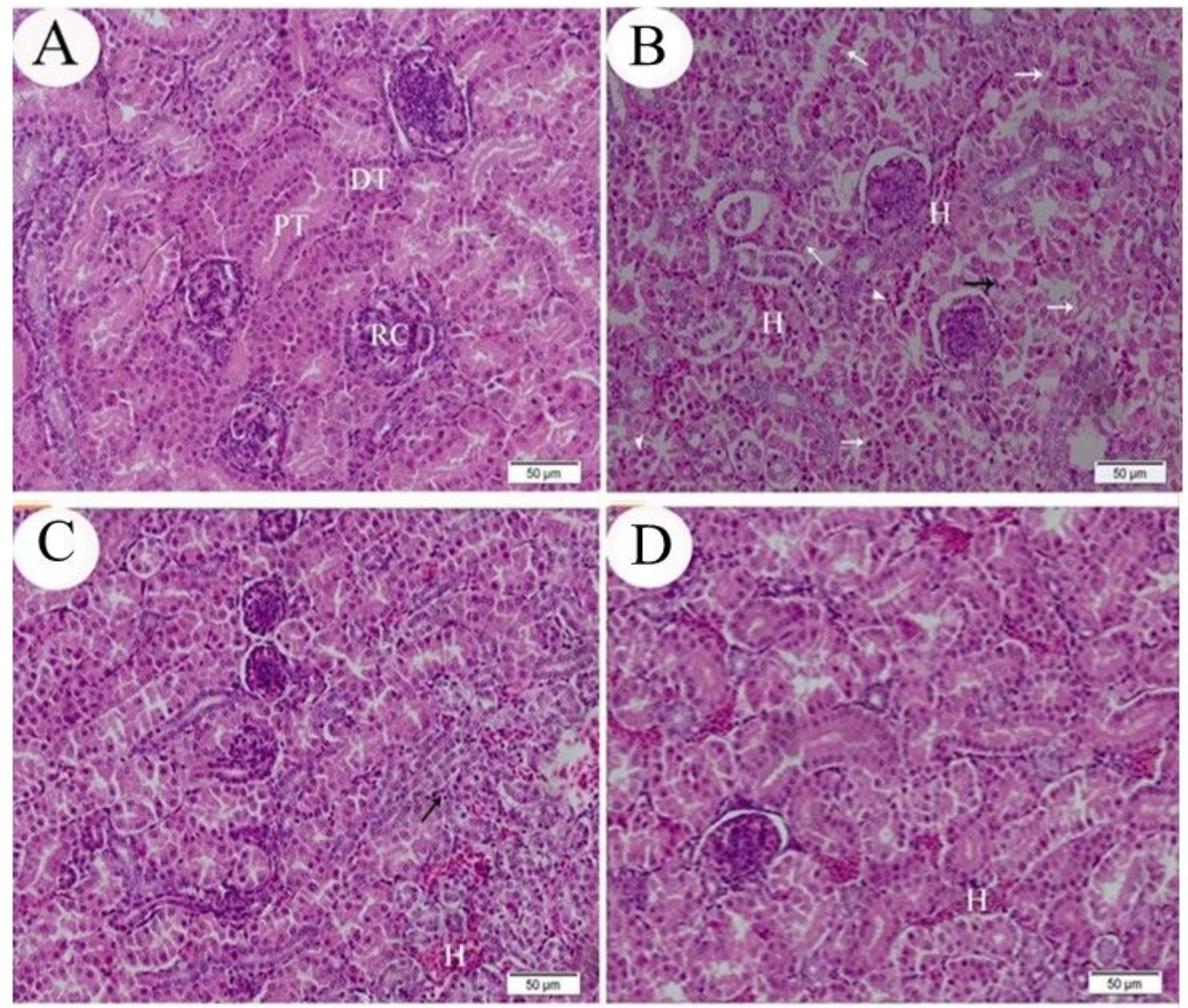

\section{Figure 8}

Representative photomicrograph of broiler kidney. A; CN group, B; Cl group, C; RI group and D; FI group. Here, Renal corpuscles (RC) and surrounding tubules; proximal tubules (PT) and distal tubules (DT); Sever congestion and hemorrhages in the peritubular capillaries $(\mathrm{H})$; Vacuolization of epithelial lining renal tubules (white arrows); Pyknosis of some tubular nuclei (arrowheads); Leukocytic infiltration (black arrows). H\&E stain. 

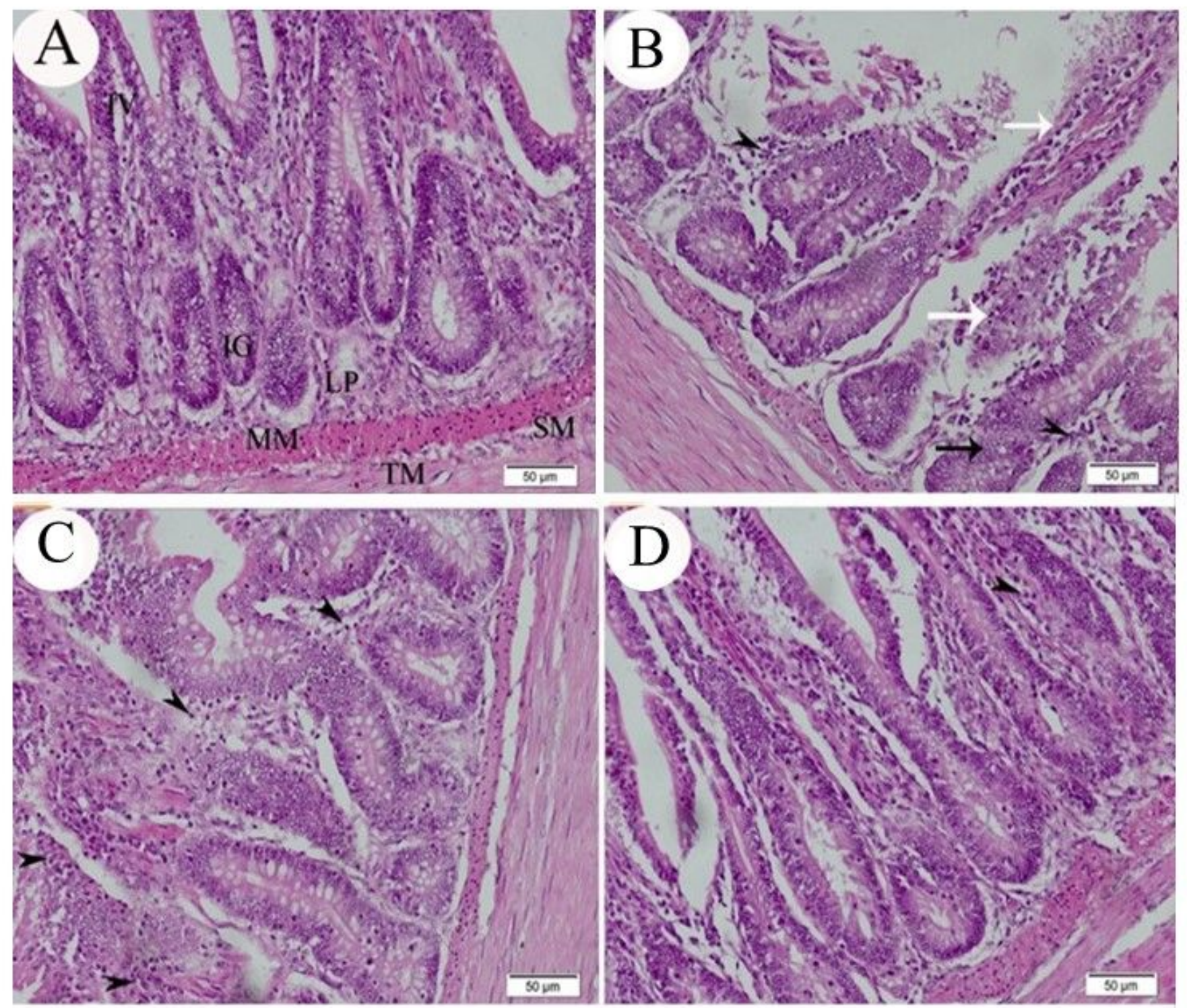

\section{Figure 9}

Representative photomicrograph of broiler intestine. A; CN group, B; Cl group, C; RI group and D; FI group. Here, Intestinal villi (IV); Intestinal glands (IG); Lamina propria (LP); Muscularis mucosa (MM); Tunica submucosa (SM); Tunica musculosa (TM); destructive intestinal villi (white arrows) and gland (black arrow); Leukocytic infiltration (head arrows). H\&E stain. 

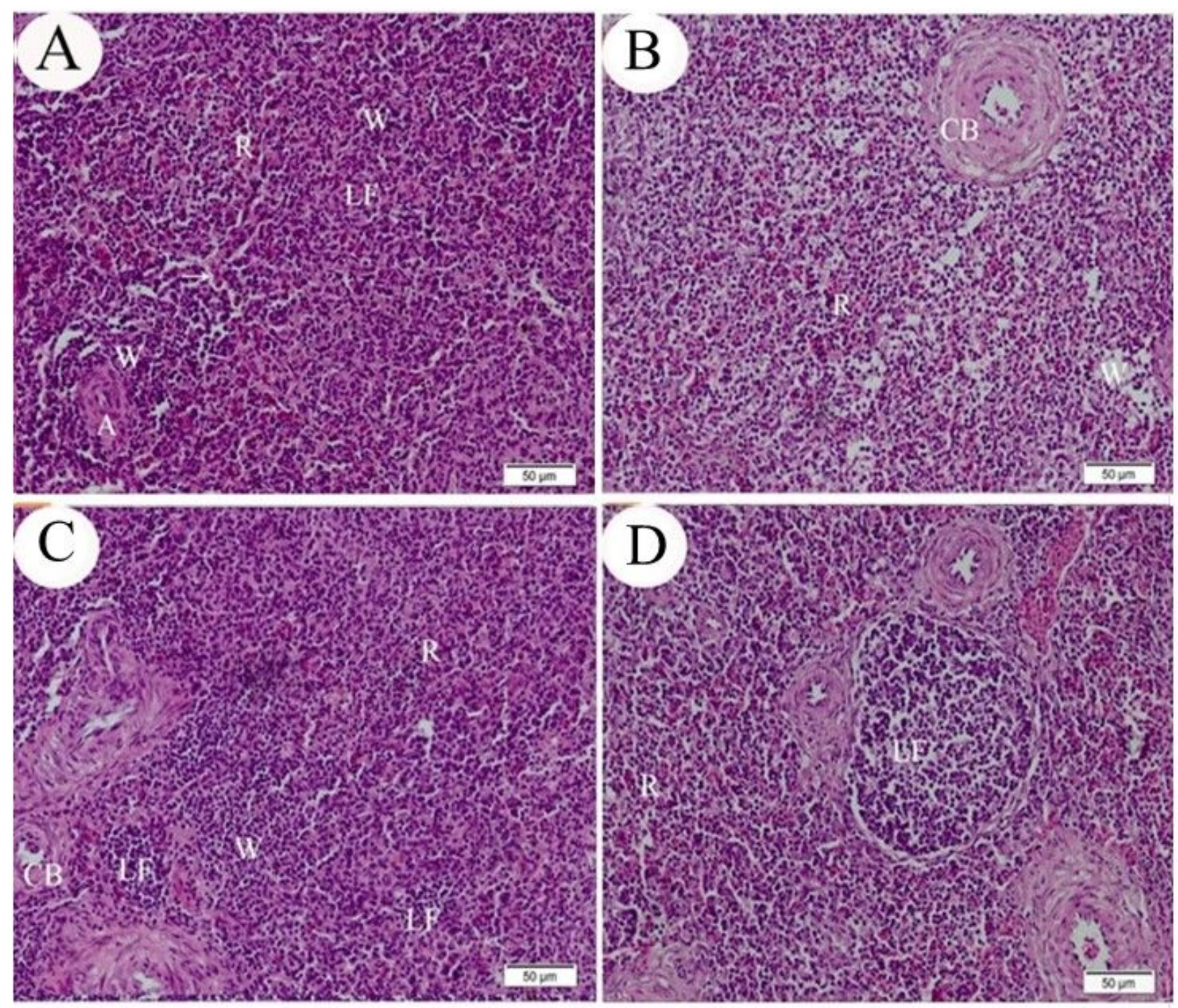

\section{Figure 10}

Representative photomicrograph of broiler spleen. A; CN group, B; Cl group, C; RI group and D; FI group. Here, Red pulp (R); White pulp (W); Lymphoid follicle (LF); Artery of white pulp (A); Congested blood vessels $(\mathrm{CB})$. H\&E stain. 

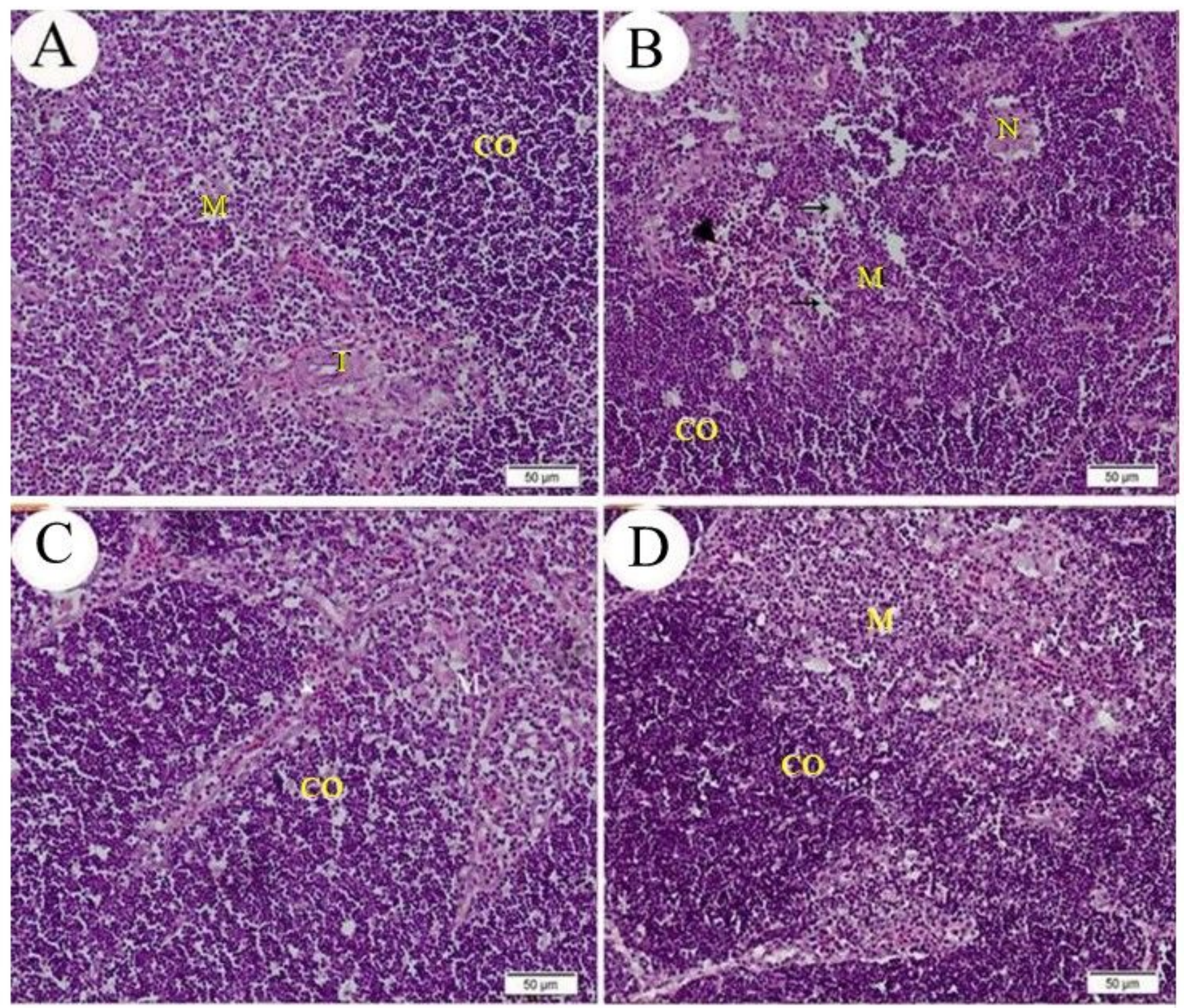

\section{Figure 11}

Representative photomicrograph of broiler thymus. A; CN group, $\mathrm{B} ; \mathrm{Cl}$ group, $\mathrm{C} ; \mathrm{RI}$ group and $\mathrm{D} ; \mathrm{FI}$ group. Here, Cortex (CO); Medulla (M); Thymic corpuscle ( $\mathrm{T}$ ); Fine connective tissue septa (white arrows); Necrotic area (N); Lymphocytic depletion (black arrows); Heamobiotic cells (head arrows). H\&E stain. 

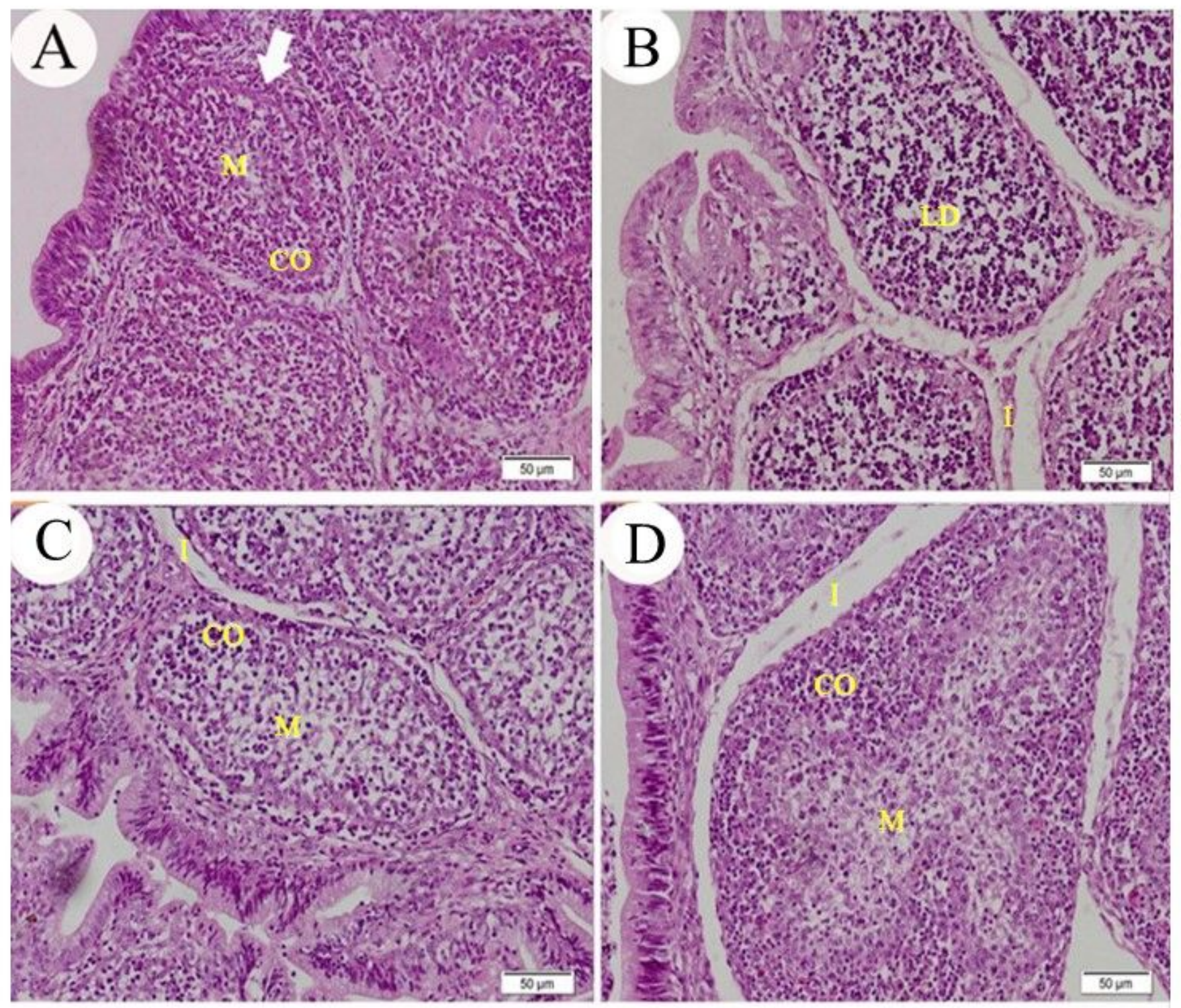

\section{Figure 12}

Representative photomicrograph of broiler bursa of Fabricius. A; CN group, B; Cl group, C; RI group and D; FI group. Here, Lymphoid follicle (thick arrow); Cortex (CO); Medulla (M); marked lymphocytic depletion (LD); Interfollicular connective tissue (I). H\&E stain. 